\title{
Geospatial Information is the Cornerstone of Effective Hazards Response
}

Every day there are hundreds of natural disasters world-wide. Some are dramatic, whereas others are barely noticeable. A natural disaster is commonly defined as a natural event with catastrophic consequences for living things in the vicinity. Those events include earthquakes, floods, hurricanes, landslides, tsunami, volcanoes, and wildfires. Man-made disasters are events that are caused by man either intentionally or by accident, and that directly or indirectly threaten public health and well-being. These occurrences span the spectrum from terrorist attacks to accidental oil spills.

To assist in responding to natural and potential man-made disasters, the U.S. Geological Survey (USGS) has established the Geospatial Information Response Team (GIRT) (http://www.usgs. gov/emergency/). The primary purpose of the GIRT is to ensure rapid coordination and availability of geospatial information for effective response by emergency responders, and land and resource managers, and for scientific analysis. The GIRT is responsible for establishing monitoring procedures for geospatial data acquisition, processing, and archiving; discovery, access, and delivery of data; anticipating geospatial needs; and providing relevant geospatial products and services.
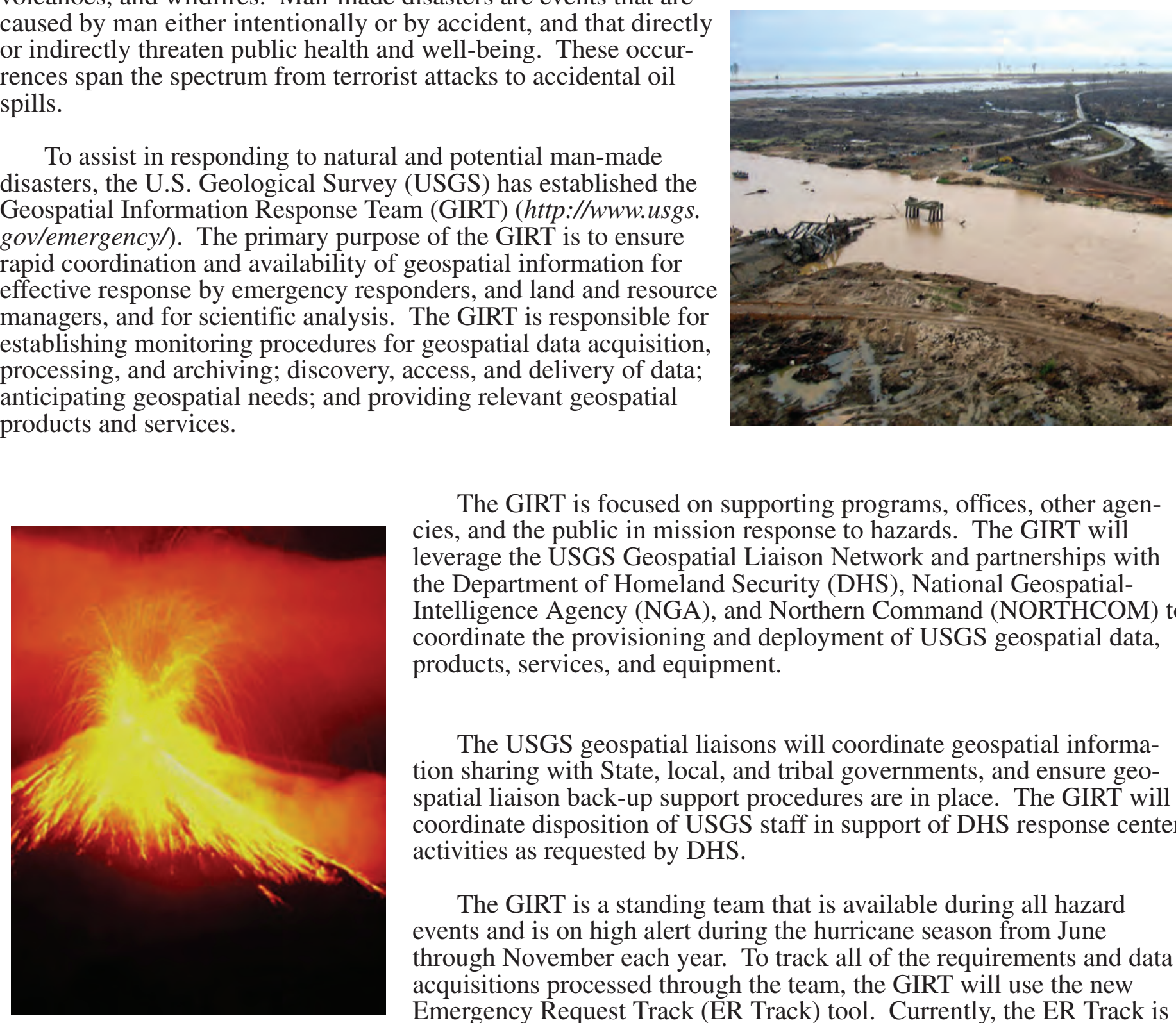

The GIRT is focused on supporting programs, offices, other agencies, and the public in mission response to hazards. The GIRT will leverage the USGS Geospatial Liaison Network and partnerships with the Department of Homeland Security (DHS), National GeospatialIntelligence Agency (NGA), and Northern Command (NORTHCOM) to coordinate the provisioning and deployment of USGS geospatial data, products, services, and equipment.

The USGS geospatial liaisons will coordinate geospatial information sharing with State, local, and tribal governments, and ensure geospatial liaison back-up support procedures are in place. The GIRT will coordinate disposition of USGS staff in support of DHS response center activities as requested by DHS.

The GIRT is a standing team that is available during all hazard events and is on high alert during the hurricane season from June through November each year. To track all of the requirements and data acquisitions processed through the team, the GIRT will use the new Emergency Request Track (ER Track) tool. Currently, the ER Track is only available to USGS personnel. 